\title{
Prestige Pricing in Markets for Luxury \& Premium Products
}

\author{
Houssam Jedidi* and Oliver Heil \\ Johannes Gutenberg University of Mainz, Germany
}

*Corresponding author: Houssam Jedidi, Johannes Gutenberg University of Mainz, Germany.

Received Date: March 28, 2020

Published Date: April 17, 2020

\begin{abstract}
This paper analyzes pricing strategies within various luxury sectors and identifies latent structures between brands and categories. Unlike previous research, we focus on firms' actual conduct, esp. on firms' pricing behavior. Through our approach, we expect to enhance the external and predictive validity of our results. More precisely, we web scraped market-data from numerous luxury maisons' products such as women's shoes, luxury cars, haute couture and men's watches (online shops owned by producers as well as other platforms). The results are rather intriguing. First, we arrived at another surprising gender-related finding: Men's luxury items (e.g. shoes and watches) are significantly more expensive than female products of the same kind. An interesting and counter-intuitive finding. Next, a hierarchical cluster analysis shows primary effects of both gender and price in defining luxury categories. We find that in the category of personal luxury goods, LV is more of a feminine brand. Next, our results show a somewhat expected positive correlation between brand value and prestige pricing. We like to think of this finding to possess much validity as it is based on primary data reflecting actual firm conduct. Interestingly, we find that in some categories, considerable competitive pressure is coming from-luxury-wise--lower-scaled companies. For example, we find evidence that Mercedes- Benz attacks Bentley and even Rolls Royce. It will be most interesting for future research to investigate the degree to which this conduct challenges established high-end manufacturers .
\end{abstract}

Keywords: luxury, prestige/premium pricing, web-scraping, online fashion, luxury cars

\section{Introduction}

Generally, charging a specific price for a product or a service depends largely on a firm' consumer and competitor strategy. That is, pricing takes into consideration customer' preferences, a firm's brand positioning as well as current, expected competitor conduct and has even be called a sufficient statistic for decision making. Moreover and generally, revenue management is more likely to focus on the bottom of the demand curve because it allows to generate higher profits. Poland and Kesgin (2018) differentiated between three strategies: cost based (firm vs. customer centered), competition based (relative to the best competitor), and value informed. The latter is strongly related to prestige/premium pricing since it is characterized by "long-term and service-based exchange, relationship focus, value creation based on holistic and shared value conception" Poland \& Kesgin [1].

Similarly, Hinterhuber and Liozu [2] defined four pricing strategies depending on customer value as well as on price related to competitors: a) low price/ high value, e.g. Ikea;

b) low price (discounters);

c) high price and low value (SKF) and, finally,

d) premium prices and high value (luxuries).

According to the authors "premium pricing [are] pricing strategies that results in prices that are high in relation to both, competitor prices and customer value" Hinterhuber and Liozu [2]. Kumcu and McClure [3] added that, contrary to the classic law of demand, prestige goods have a "backward bending demand" such as fine jewelry and luxury cars Hawkins [4]. In the same context, Vigneron and Johnson [5] studied the relationship between exclusivity, price and the perceived prestige value. Consequently, the authors introduced four different customer groups which differ in their desires and perceptions of prestige. For instance, both Veblenian and snobs weight price as key prestige indicators. Yet, the decision either or not to buy the product depends on their self-consciousness. Similar findings were presented by Kumcu 
and McClure [3] where they demarcated this strategy as decisive, especially in an encumbered market with high competition. As an example, the authors described how Loewe succeeded in applying a value-based strategy through a meaningful differentiation. At a certain point, the company failed to preserve this advantage when the premium price obviously exceeded the real value. Moreover, brand value, capabilities (customer-experience, solution-centric business models), technological competences such as value-based selling and data-based algorithms are major aspects challenging todays' companies when applying prestige pricing. In line with this, Kumcu and McClure [3] concluded that brand value moderates this pricing approach. This is, at least in part, due to luxury goods being generally sold by monopolists/oligopolists or monopolistically competitive firms Perrault and McCarty [6]. In this context, Perrault and McCarty [6] affirmed that firms' dimension and values are important asset for marketing power as well. They stated out that the relationship between the costs and the purchased quantity is not necessarily adverse. In numerous cases, the desire to acquire certain goods increases expressively as its price increases. Accordingly, the demand curve slopes upward. Relatedly, Kapferer, Klippert and Leproux [7] studied the customers' luxury perception across various cultures. They acknowledged significant cultural and social effects on the luxuriousness perception in relationship to price. Moreover, they stated out that high-end manufacturers have larger price boundaries than premium or mass brands.

Overall, thesestudies focused on the customer perspective and failed to sufficiently incorporate the firm's perceptive. Furthermore, there units of analysis seem to be a bit limited causing their findings to suffer from a lack of generalizability. That is, the all concentrated on a few markets only such as fashion and/or jewelry and overlooked other segments such as the automobile industry which is leading the high-end segment Bain and Company [8]. To overcome the aforementioned limitations, we web scraped data from numerous luxury firms across various industries:

I. Cars: Koenigsegg, Bugatti, Maybach, Ferrari, Aston Martin, McLaren, Pagani, Rolls Royce, Bentley etc.,

II. Pret a Porter and shoes: Gucci, Chanel, Burberry, Hermes, Dior, Versace, Christian Louboutin, etc.,

III. Bags and Accessories (Gucci, Chanel, Burberry, Dior, Hermes, Miu, Louis Vuitton, Prada), and

IV. Watches (Rolex, Patek Philippe, Breitling, Cartier, IWC, Nomos, Omega, Tag Heuer, etc.).

Unlike previous investigations, we aim, as indicated above, to use both, existing pricing philosophies and real market data to better describe pricing tactics and product categorizations in markets for premium and luxury goods. Additionally, we want to shed light on the relation between brand value and the application of premium pricing.

\section{Application of Premium Pricing: Hypotheses}

The so-called luxurification of many societies as well as the increasing global wealth result higher wtp for luxury and aspirational goods. Companies have therefore the opportunity to extent their services and to expand the brand. Oancea [9] studied the challenges of prestige pricing in commercial aviation. She pointed out that different tactics are required not only between airlines but also within the same airline depending on the aircraft. For instance, she highlighted a significant growth in premium ticket sales in the USA from 2.3\% in 2012 to around 4\% in 2015. Similarly, Yeoman and McMahon [10] highlighted the increasing wtp for goods to increase happiness and well-being. It appears that consumers trade more up and down in their purchases depending on the relative importance of certain category. For instance, a consumer may be willing to pay a prestige price for a Ferrari but save money by frequenting a low-barber shop.

This range of consumption choices or disharmony of consumption poses challenges and opportunities for firms across all industries. First, it allows to broaden the products' accessibility. Thus, depending on their needs (financial, social, individual and functional) clients can switch between brands and purchase the product that better fits them. Subsequently, loyalty and brand relationships can easily be affected. Second, trading-up allows for personalization in most levels, and therefore increases profit. As an illustration, the remarkable price increase for a Mercedes C 200 CDI from €24.600 in 2004 to €27.750 in 2008 and to €39.127,20 in 2017 Yeoman \& McMahon [10], Mercedes-Benz [11-13]. This is not only caused by the increasing wealth in today's society but also due to an intensive competition on the segment. Subsequently, customers face a wider range of features and extra packages that motivate them to upgrade. In similar context, Hinterhuber and Liozu [2] studied the potential and the challenges facing premium pricing. They listed five decisive points. First, companies applying premium pricing approaches should be able to justify this prime. The authors underlined the functional, financial, social aspects as well as the brand worth as major factors legitimizing the charge of a premium price compared to the competition. As an illustration, a comparison of two compact cars: Audi A3 and a Mercedes A-Class (with similar features) gave a price difference of around $€ 5.000$ in favor of Mercedes. Subsequently, history, craftsmanship, know-how and the brand value argue for this price premium. For instance, a Mercedes delivers higher social values (status, recognition, prestige) as well as a higher safety level through a-relatively- better image. Second, the technological advance is a major issue across all industries. High-tech builds the most important functional aspect for today's clientele. As an illustration, the following features generate competitive advantages in many industries: self-drive and online presence (cars, Airplane, etc.); precision, perfection, "smart" (watches, Tv, computer, etc.) and augmented reality (fashion, etc.). Hinterhuber and Liozu [2] specified the indispensability of both, 
developing integrated solutions focusing on customer experiences and brand relationships (attachment, love, trust, etc.) and a valuebased selling (capability to apply premium pricing strategies with a convenient team) in shaping the brand. Consequently, prominent firms such as LV, Chanel and Ferrari are continuously forming their personal to better mirror the brand norms and philosophy. Also, their communities and clubs are positively affecting the brand image through various events (internal/external). Finally, AI (artificial intelligence) and the capability to dynamically state/react to price changes is a major issue. Therefore, leading companies are steadily monitoring the online shops (own and foreign) as well as social media platforms for a better and a faster reaction to customers (reviews) or to the competition (price changes). We build on research on brand value and extend it to the domain of prestige pricing. As a result, we posit the following linkages:

H1a: High brand Value facilitates/correlates with the implementation of prestige pricing.

H1b: Prestige pricing is generally executed by larger, traditional incumbent luxury brands (since high brand value correlates with the latter brands).

Harkison, Hemmington and Hyde [14] recognized a huge potential applying prestige pricing in the hospitality sector. Due to the evolving preferences for more comfort in hospitals as well as increasing wealth, the global hospitality sector is moving from being product-focused to experience-focused. Properties, especially lodges need to demonstrate why they justifiably demand premium prices by providing an exceptional value and a memorable experience. Also, hospital companies are creating new categories which are self-styled and translate their firms' philosophy toward new services and amenities Milburn \& Hill [15]. Nonetheless, the hospital sector is facing many challenges. Luxury accommodations need to update, so a so-called "wow" factor persists. Similarly, such efforts are needed to optimize customer experiences, to gain a source of differentiation and to generate other competitive advantages Johnson et al [16]. Relatedly, Harkison [17] showed that evolving tastes necessitate greater convenience like co-creating and shared experiences. All in all and not surprisingly, luxury comes with a high price and this seems to hold especially true in the hospital sector. According to Pohland and Kesgin [1], in the somewhat related business of hotels, upscale hotels make numerous efforts to justify high pricing and such efforts often include unique and personal service offers-similar to high-end hospitals. Thus, one might argue that the luxury hospitality and hospital market is experiencing much competition due to evolving consumer tastes as well as service improvements by lower tier producers. In line with the aforementioned much research suggests that high-end manufacturers should maximize prices rather than market share (Johnson et al., 2009), Harkison [17], Kapferer \& Tabatoni [18]. For completeness, a cautionary note seems appropriate as However, Kapferer and Tabatoni [18] accentuated mishandling price strategies to show the risks of poorly executed prestige pricing.
When introducing entry models, Jaguar has lost prestige and cache causing it to become unable to demand premium prices anymore. Subsequently, the brand was diluted-it is now owned by Tata, a conglomerate from India. In the same context, Fassnacht, Kluge and Mohr [19] compared traditional and prestige pricing policies. They concluded that luxury pricing is beyond monetary values, it is more about finest quality and unforgettable moments. Moreover, they highlighted that the management of luxury brand is significantly different to other brands and don't follow the traditional marketing rules (stability, no discounts etc.). Agreeing with previous works, the authors accentuated the importance of high and constant prices for the firms' success. For instance, Louis Vuitton has never reduced prices which has a positive effect on profitability. Similar findings are presented by Kapferer [20] as he encouraged brands to increase the average price since the middle class is getting richer. Thus, brands should not trade down and we, thus, posit the following hypothesis.

H2: "Meaningful differentiation" justifies charging higher prices across categories. Note: By meaningful differentiation we mean that products exhibit exceptional features, exclusivity, uniqueness compared to traditional competitors.

Kapferer, Klippert and Leproux (2013) studied consumers' psychology of luxury prices by means of various brands like Mouboussin, Tiffany, Dior and Louis Vuitton. They acknowledged the intensive competition in the luxury market due to various strategic goals, e.g., in the context of product line extension. The luxury industry presents a paradox since, higher prices causes both, appealing and churning. For instance, snobs are more willing to buy expensive merchandise whereas conformists prefer moderate ones-yet both may purchase luxurious products.

Trading- up (-down) is advantageous for many manufacturers especially to those possessing higher price latitude. However, for these extensions to work, they need to fulfill three main criteria, otherwise brand dilution becomes likely (Kapferer, Klippert \& Leproux 2013). First, the prices of the entry lines must reiterate the repositioning of the brand vis a vis competitors' entry line. Second, it should deliver the key aspects of the brand as well as its' DNA. Lastly, the charged price should clearly be above the normal line to signify the difference between non- and luxury brands. We build on these notions to offer our third hypothesis by linking luxury brands' pricing potential to their products in various categories, causing us to conjecture:

H3: Luxxury brands can charge higher prices than premium firms across all categories.

\section{Gender Effects}

Additionally, many authors (e.g. Kapferer [21], De Block and Dewitte [22], Griskevicius et al. [23]) studied the gender effect on consumption behavior. Kapferer (2010) affirms that the "tardy" wedding in today's society gives people more funds to enjoy their lives and to shape their consumption into delight. Additionally, 
there exists a significant gender difference when judging others. For instance, men evaluate woman strongly using the female's physical appearance. Rather asymmetrically, women appraise men according to their possessions and (tangible) social achievements Buss [24]. Therefore, men are more likely to exhibit a higher willingness to pay for luxurious products that signal larger material possessions and achievement of higher social status. The we posit hypothesis 4:

H4: Luxury categories that signal high material possessions and (tangible)

Social achievement, luxury products focusing on male consumers exhibit

higher prices that similar products targeted at female luxury consumers.

\section{Empirical Study and Results}

As mentioned above, this paper aims to analyze various forms of applying prestige pricing in the luxury market. Importantly, identifying latent structures as well as relationships between brand worth, pricing strategies, and the choice of certain categories are decisive. Contrasting previous works which, principally, investigated consumer-based insights to evaluate both brand values as well as their pricing approaches, we considered the firms' side. Towards achieving our research goals, we web scraped data from numerous high-end marketers across many industries such as women's shoes, men's watches, accessories, bags and cars. The data weres collected between March and Mai 2018 (using Rvest for webscraping) and originates either from sellers' website or from best known and established online shops . To operationalize our search, we selected the brand, the category, the name of the product as published by the seller, its description (e.g. constitution, color, design, extra features) as well as its price. For fashion goods (Pret a Porter, watches, bags, shoes and accessories) and jewelry, it was important to add a variable characterizing the source of information (own/foreign web). This would help assessing the exclusivity aspect as well as the brands' philosophy. For the car industry, the data include brand, model, price, hp, engine, $\mathrm{km}$, status, and construction year. We also added some influenceable premium brands such as MercedesBenz, BMW, Audi, Tesla, Jaguar etc. The dataset contains cars from 1925 to 2018 made by prominent manufacturers including Ferrari, Pagani, Koenigsegg, Aston Martin, Lamborghini and Bugatti.

\section{Car Industry}

The primary analysis of premium brands shows exceptional characteristics for Mercedes-Benz among other premium manufacturers. For instance, the firm has a price range from $€ 60.000$ to $€ 3.000 .000$. The most expensive cars are an S650 Pullman Guard VR10 for €3.000.000, a SLR Stirling Moss limited (1 of 75) for €2.622.000 and a G 65 AMG Landaulet Stock (1 of 99) for €1.273.600. Followed by Land Rover, Porsche and BMW which present a comparatively slighter price distribution (Figure 2). Additionally, the company offers goods which are more sophisticated and expensive than established high-end manufacturers such as Bentley, Ferrari, Aston Martin, Maserati and Lamborghini. Our findings are rather interesting. The analyses illustrate a decreasing pricing slope for premium brands from 2000 until 2017. It appears that premium manufacturers such as BMW, Audi, Jaguar are more willing to trade down to reach mass clients in an effort to increase their profit and market share (models like the A1, Q1, X1 etc.). Another explanation could be the learning effect as well as the economies of scale which reduce the costs, and subsequently, allow a smaller price to be charged.

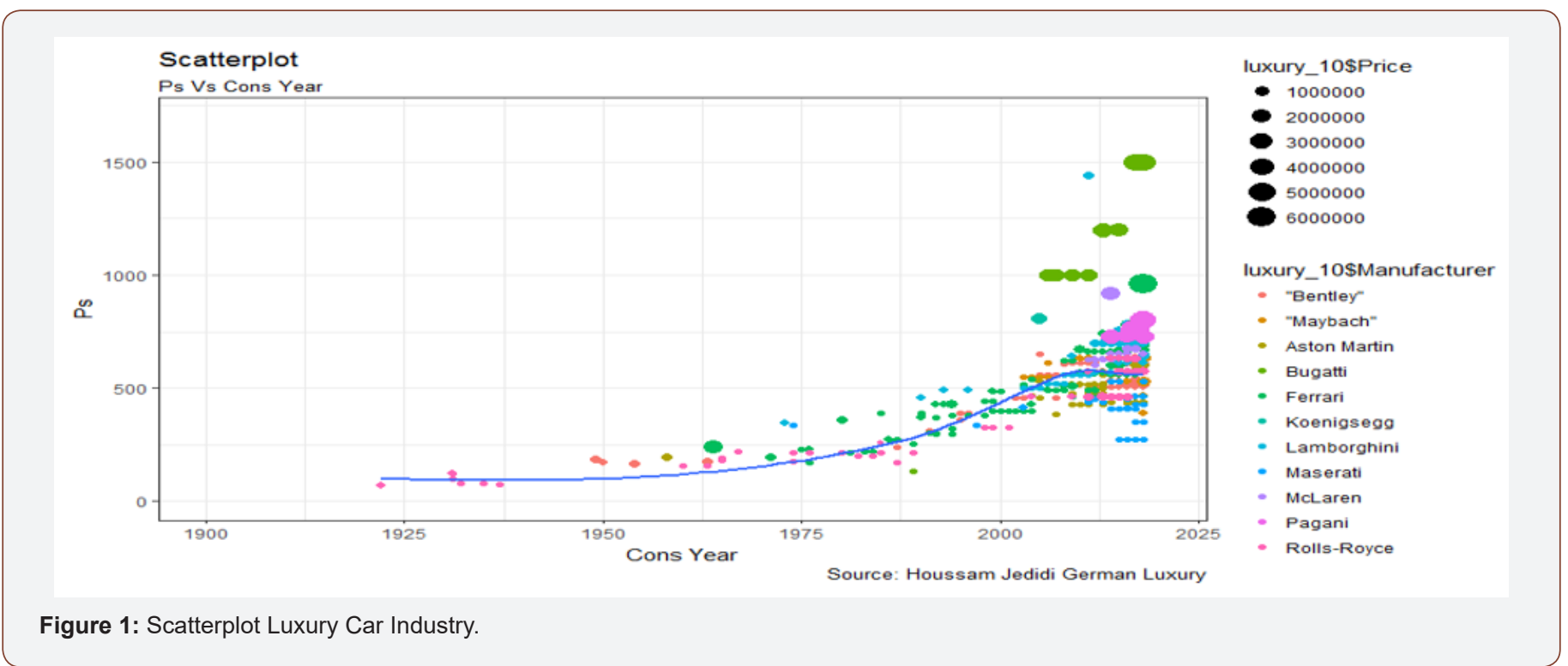

Remarkably, in 2018, Mercedes-Benz displays an aggressive increase in prices which clearly exceeds competitors. For instance, the brand charges eight times more than (in)-direct competitors for certain, unique models (Figure 2). Therefore, brand extension rules according to Kapferer et al. [25] are broken, since they affirmed that luxury brands have a significant larger price latitude than their counterparts. Therefore, they generally charge higher prices across all categories. Interestingly, unlike premium brands, 
luxury manufacturers appear to trade-up and increase both their prices as well as the quality of their goods (the latter, for example, signaled through attributes such as horsepower). Remarkably are Bugatti and Pagani which show an enormous, almost exponential increase in quality (e.g., hp) and price. For example, Pagani charges around €6.000.000 for a Zonda model with 750hp and Bugatti $€ 3.689 .000$ for a Chiron with $1500 \mathrm{hp}$ (Figures 1 \& 2). Interestingly, is that luxury cars have a very slight drop in value/worth over time, e.g. Ferrari, Rolls-Royce, Aston Martin and Bentley. These insights suggest that there is little orno significant influence of time and usage on the value/worth which converges to the fundaments of luxury (longevity, heritage and perpetuity). That is, H1a, H1b, H2 are confirmed and we fail to accept H3 .

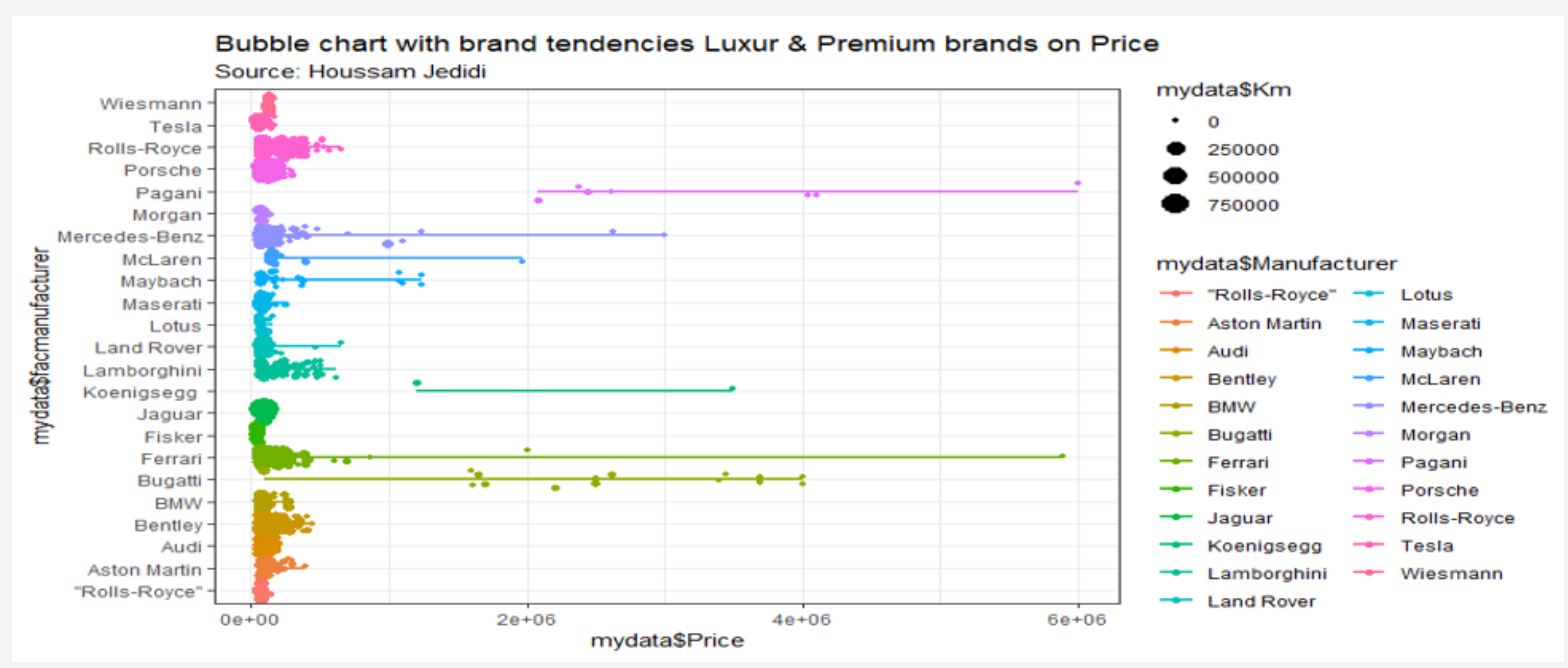

Figure 2: Bubble Chart Luxury and premium Brands on Pricing.

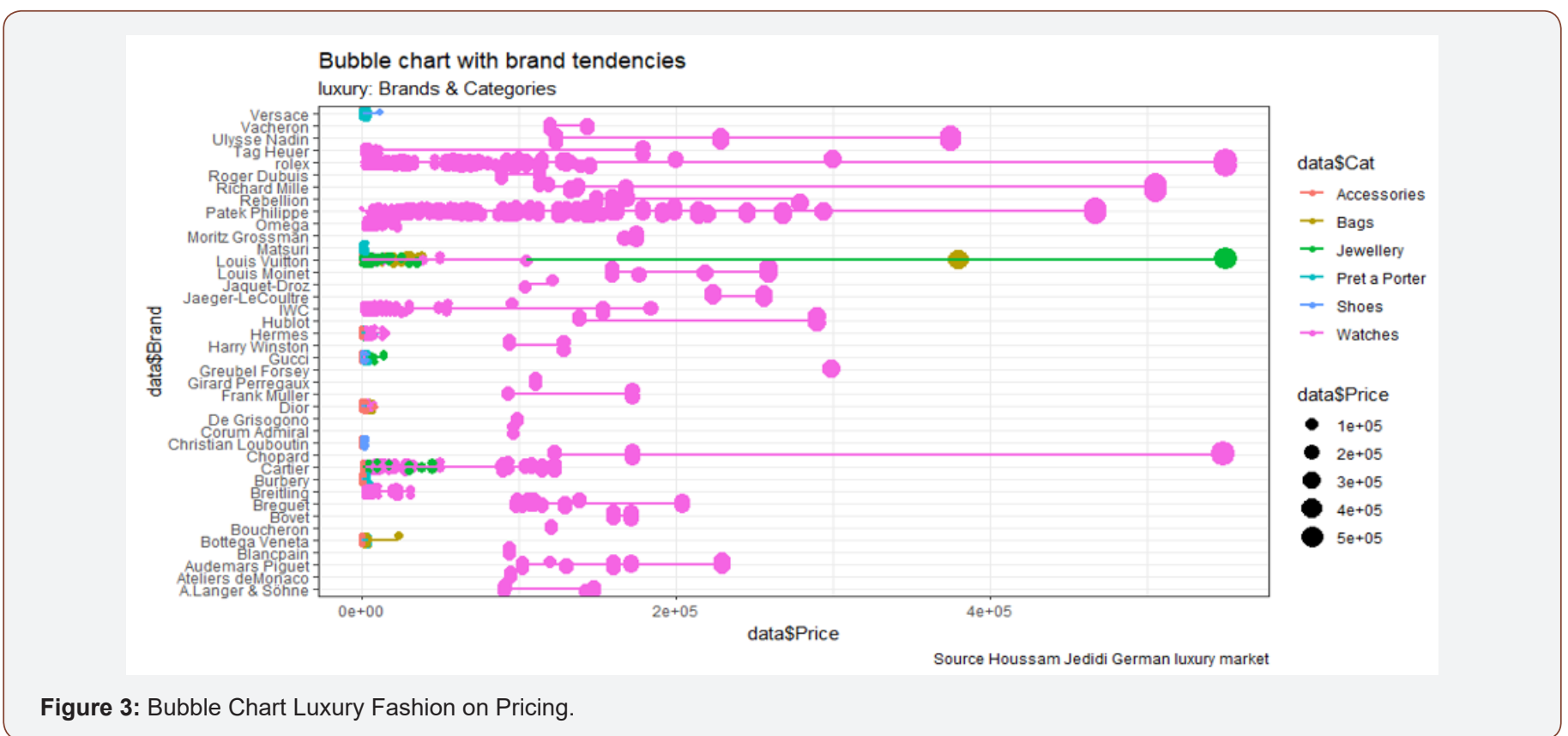

\section{Personal and Fashion Goods}

The data set encloses five traditional categories (accessories, bags, jewelry, pret a porter, shoes and watches). The first analysis gives a clear summary of brand tactics and their pricing strategies. For example, companies like Vacheron, Tag Heuer, IWC, Patek Philippe, Rolex, Breguet, etc. are specialized in manufacturing luxury watches and leading their industries. Other companies such as Louis Vuitton, Hermes, Cartier and Gucci are multi-layered and market to many or most categories. Interestingly is the strategy of
Louis Vuitton, which is not only simultaneously aiming all segments but leading them as well. As an illustration, their brand has the widest price distribution and it postulates the highest prices among the available data. A LV Dentelles de diamonds or a Dayton watch cost $€ 550.000$ followed by a Chopard lady watch for $€ 548.612$ and a Richard Mills watch for €505.000. Accordingly, H1a and H1b are also supported from that angle.

In order to better characterize pricing strategies in the luxury market as well as to identify latent structures, next, we conducted 
a cluster analysis for both segments (automobile \& personal goods). After trying various methods, the decision was in favor of hierarchical cluster method which, unlike other approaches such as k-means, doesn't require a predefinition of the groups. Hierarchical

Table 1: Hierarchical Clustering (Luxury market).

\begin{tabular}{|c|c|c|c|c|c|c|}
\hline Group & Year & Km & Ps & Price & Status & Engine \\
\hline Typical luxury & 0.1529604 & -0.01696398 & 0.4665855 & -0.03738125 & -0.2611216 & 0.5596224 \\
\hline Daily Lux cars & 0.4427336 & -0.29304472 & -0.7769324 & -0.21183237 & -0.2611216 & -1.4434612 \\
\hline Old timer & -2.8120614 & 1.39612578 & -0.8997623 & -0.02781276 & -0.1741311 & 0.4072902 \\
\hline New/EVs/PHEVs & 0.3146437 & -0.24566116 & -0.1818221 & -0.09173503 & 3.8274305 & 0.8691844 \\
\hline Ultrasportscars & -0.2702272 & -0.60312364 & 4.0564638 & 9.08241031 & 0.2198846 & 0.5334778 \\
\hline
\end{tabular}

In the car industry, the output shows the existence of five clusters: typical luxury cars with a "moderate" power like Aston Martin (DB9, Vanquish, V8), Lamborghini (Aventador, Huracan), Bentley (Continental, Flying, Bentayga), Mercedes (SLS AMG), and Porsche (911). The second group represents "regular" cars with moderate horsepower ( 250-350) and -generally- diesel engine such as a Maserati (Quattroporte, Grandturismo), Mercedes (S, CLS, GL, G), BMW (7-series,6-serie, X-series), Land Rover (Velar). Next and thirdly, old timers (Km-eaters) forms the third cluster with cars like Jaguar (E type, XK120, Atlantis), Mercedes (SE, SL), Ferrari (Testarossa, 308, 246) and Porsche (911, 930, 356C). The fourth group encompasses new vehicles as well as EVs and PHEVs like Tesla (Model S, X) and Fisker (Ever, EcoSport). Lastly, Bugatti (Veyron, Chiron), Koenigsegg (CCR, CCXR), Ferrari (LaFerrari, 488) and Mercedes-Benz (S650, SLR, G) build the ultra-luxury group. cluster analysis is a heuristic method that, based on the distances between various datapoints, comes out with the best combination and grouping (Table 1).

Plotting the distribution of the manufacturers on the five clusters provides interesting information about the companies as well as their philosophies (Figure 4). Exclusive brands like Koenigsegg and Bugatti are representing the fifth group with extremely expensive products. Others like Audi, BMW, Jaguar and Land Rover are not only dominating the diesel and daily luxury cars with models like 7 series, A8, Q7, Velar, Discovery, XF and XJR but also providing some products which flow in the typical luxury cars group (M6, M5, R8; RS6, F Type). Those companies appear somehow conservative and focusing on this market for daily/accessible luxury cars taking advantage from their know-how, experience and traditions. Their pluck stops at some accessible luxury models. However, Porsche is present in four segments with various models and is therefore, one of the most representative and successful companies.

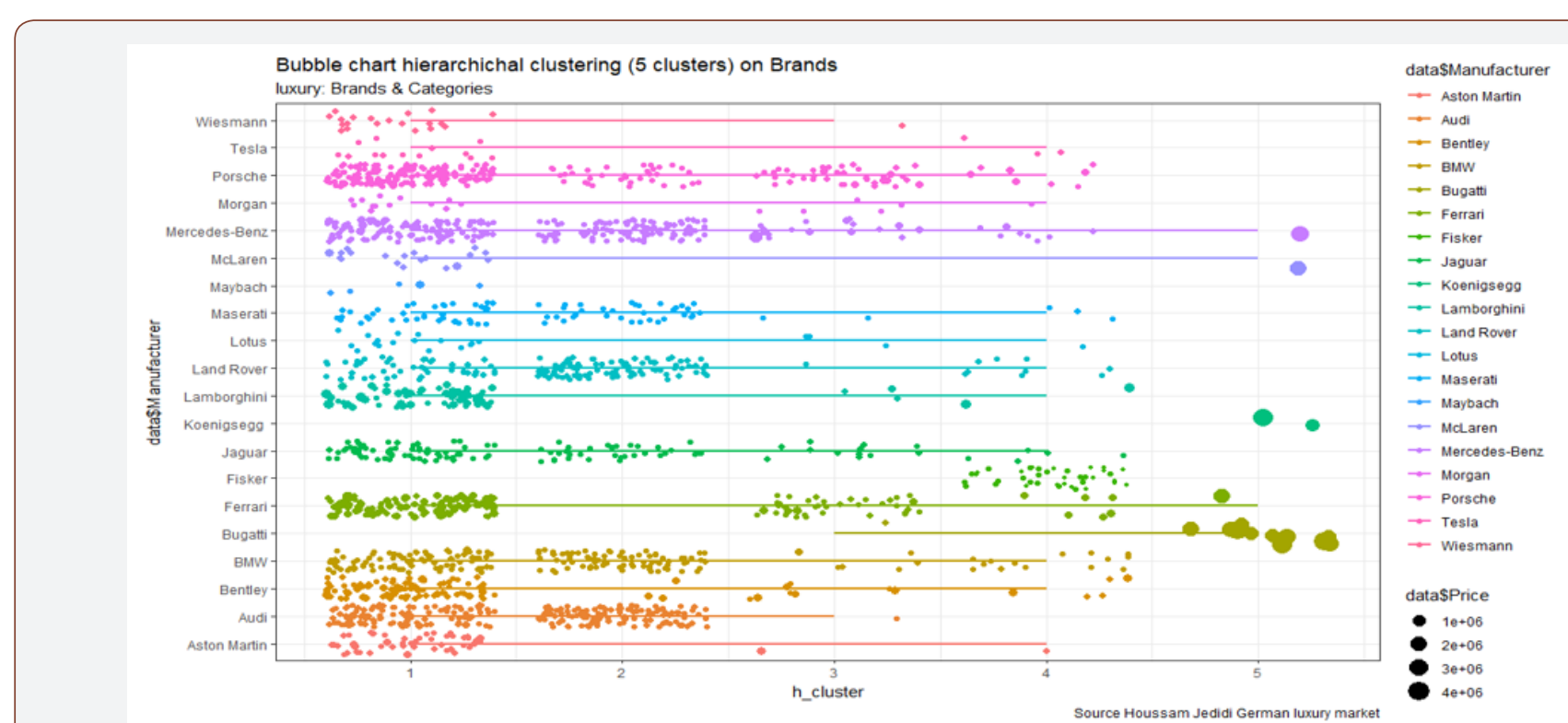

Figure 4: Hierarchical Clustering Luxury Automobile.

Likewise, Ferrari is present in four groups (upper tier). Ferrari doesn't really produce entry lines and is limiting all its models to protect the brand. For instance, owning the financial means is not enough to acquire the brand. Ferrari will often need to see a history of ownership, afterward the decision will be made. This is reflective of an effort to prevent consumers who don't really respect the brand but purchase a car to sell it at a profit afterwards. Fascinatingly, is the strategy followed, in a sense, by Mercedes-Benz. The premium manufacturer is not only dominating the mass/premium market with models like the A, B,C and E-class but the only brand which is present in all five clusters. Subsequently, the brand broke all pricing rules and shows a high willingness to take risks which, as it is seemingly successful, is shaping it upward. 
In a next step, we selected the most influenceable firms that are successfully applying a prestigious pricing tactic. For this issue the choice was to conduct hedonic regression models to better characterize their policy. To highlight some attributes like the status of the car (used vs. new) we employed the effect coding approach. Also, the choice was to set the semilogarithmic form as it has been proven to fit the data best. The model employed is represented as follows:

\section{$\llbracket \log \rrbracket_{-}\left(\left(\left(\right.\right.\right.$price $\left.\left.\rrbracket_{-} \mathrm{i}\right)\right)=\alpha+\mathrm{X}_{-} \mathrm{i}^{{ }^{\prime}}+\varepsilon_{-} \mathrm{i}$}

This model highlights the logarithm of the price in relationship to the absolute values of its' characteristics (relevant features). Also, using natural logarithms allows, in such a model, to have an estimate of the percentage increase in price due to a one-unit change in a particular characteristic or in quality while holding the level of other variables constant. The output highlighted the pricing tactic applied by Mercedes-Benz which differentiates it from traditional competitors such as BMW and Audi. Note that there exist no significant differences between prices of cars across all categories. That is, at a given price, we are unable to predict the model as well as the category (Table 2).

Table 2: Gender and Web Effects on Luxury pricing.

\begin{tabular}{|c|c|c|c|c|c|c|}
\hline \multirow{2}{*}{ Accessoires } & Gender & $-8.515 e-02$ & $7.854 \mathrm{e}-03$ & -10.842 & $<2 \mathrm{e}-16$ & $* * *$ \\
\hline & Ownweb & $7.249 \mathrm{e}-02$ & $8.879 \mathrm{e}-03$ & 8.164 & $3.59 \mathrm{e}-16$ & $* * *$ \\
\hline \multirow{2}{*}{ Shoes } & Gender & $6.200 \mathrm{e}-03$ & $6.666 \mathrm{e}-03$ & 0.93 & 0.352 & \\
\hline & Ownweb & $-1.136 \mathrm{e}-01$ & 7.536e-03 & -15.07 & $<2 \mathrm{e}-16$ & $* * *$ \\
\hline \multirow{2}{*}{ Pret a Porter } & Gender & $4.667 \mathrm{e}-04$ & $6.400 \mathrm{e}-03$ & 0.073 & 0.942 & \\
\hline & Ownweb & $1.128 \mathrm{e}-01$ & 7.236e-03 & 15.584 & $<2 \mathrm{e}-16$ & $* * *$ \\
\hline \multirow{2}{*}{ Bags } & Gender & $1.497 \mathrm{e}-01$ & 5.733e-03 & 26.116 & $<2 \mathrm{e}-16$ & $* * *$ \\
\hline & Ownweb & $-1.069 \mathrm{e}-02$ & $6.482 \mathrm{e}-03$ & -1.650 & 0.099 & \\
\hline \multirow{2}{*}{ Watches } & Gender & $-1.146 \mathrm{e}-01$ & 7.765e-03 & -14.764 & $<2 \mathrm{e}-16$ & $* * *$ \\
\hline & Ownweb & $-8.587 \mathrm{e}-02$ & $8.779 \mathrm{e}-03$ & -9.781 & $<2 \mathrm{e}-16$ & $* * *$ \\
\hline \multirow{2}{*}{ Jewelry } & Gender & $4.339 \mathrm{e}-02$ & $3.764 \mathrm{e}-03$ & 11.529 & $<2 \mathrm{e}-16$ & $* * *$ \\
\hline & Ownweb & $2.489 \mathrm{e}-02$ & $4.255 \mathrm{e}-03$ & 5.849 & $5.09 \mathrm{e}-09$ & $* * *$ \\
\hline
\end{tabular}

Our results clarify the current discussion across various social media platforms and magazines about the similarity across numerous models like the $\mathrm{S}, \mathrm{E}$ and $\mathrm{C}$ classes. Also, the results shed light into the influence on both customer perceptions and WTP. However, this is not the case for BMW and Audi. As an illustration, Audi appears to be trying to explicitly demonstrate the boundaries between their models to better differentiate their customers. This could be advantageous, especially for clients who are primarily seeking differentiation and prestige. Those customers need clear limits between the diverse models which might be a motivation for upgrading within the brand. Contrarily, this might be disadvantageous for buyers who seeks identification (Bandwagon).
That is, owning an A4 has no to little relationship with people who drive an A8. Such clients are more likely to buy a Mercedes esp. as the classes are exceedingly interrelated. Remarkably, is the dissimilar effect of some attributes like driven distances and status on prices of luxury car manufacturers. As an example, a high number of miles/kilometers driven minimally affects the price of a Porsche (followed by Mercedes-Benz), but decisive for Ferrari which is more known for exclusivity and rarity. Though, Porsche points toward quality as $2 / 3$ of produced 911 are still registered and possess the lowest coefficient of "production year" on the price of the car (Table 3).

Table 3: Prestige Pricing for most influential brands.

\begin{tabular}{|c|c|c|c|c|c|c|c|c|c|c|c|}
\hline \multicolumn{6}{|c|}{ Louis Vuitton } & \multicolumn{6}{|c|}{ Hermes } \\
\hline & Estimate & Std. Error & $t$ value & $\operatorname{Pr}(>|t|)$ & & & Estimate & Std. Error & $\mathrm{t}$ value & $\operatorname{Pr}(>|t|)$ & \\
\hline (Intercept) & 6.44199 & 0.07671 & 83.982 & $<2 \mathrm{e}-16$ & $* * *$ & (Intercept) & 5.51676 & 0.05287 & 104.336 & $<2 \mathrm{e}-16$ & $* * *$ \\
\hline Gender & 0.12559 & 0.03003 & 4.183 & $3.19 \mathrm{E}-05$ & $* * *$ & Gender & 0.05258 & 0.03974 & 1.323 & 0.187 & \\
\hline CatBags & 1.70998 & 0.0714 & 23.949 & $<2 \mathrm{e}-16$ & $* * *$ & Catjewellery & 1.11088 & 0.09983 & 11.127 & $<2 \mathrm{e}-16$ & $* * *$ \\
\hline CatJewellery & 1.53533 & 0.12779 & 12.014 & $<2 \mathrm{e}-16$ & $* * *$ & CatPret a Porter & 0.87959 & 0.07998 & 10.997 & $<2 \mathrm{e}-16$ & $* * *$ \\
\hline CatShoes & 0.59166 & 0.08062 & 7.339 & $5.21 \mathrm{E}-13$ & $* * *$ & CatWatches & 2.88362 & 0.10376 & 27.792 & $<2 \mathrm{e}-16$ & $* * *$ \\
\hline CatWatches & 2.09559 & 0.10184 & 20.577 & $<2 \mathrm{e}-16$ & $* * *$ & Ownweb & NA & NA & NA & $\mathrm{NA}$ & \\
\hline Ownweb & -0.37612 & 0.05999 & -6.269 & $5.88 \mathrm{E}-10$ & $* * *$ & \multirow{2}{*}{\multicolumn{6}{|c|}{ Multiple R-squared: 0.7211 , Adjusted R-squared: 0.7179}} \\
\hline Multip & quared: 0. & 01, Adjuste & R-square & 0.6072 & & & & & & & \\
\hline
\end{tabular}




\begin{tabular}{|c|c|c|c|c|c|c|c|c|c|c|c|}
\hline \multicolumn{6}{|c|}{ Mercedes-Benz } & \multicolumn{6}{|c|}{ Ferrari } \\
\hline & Estimate & Std. Error & t value & $\operatorname{Pr}(>|t|)$ & & & Estimate & Std. Error & t value & $\operatorname{Pr}(>|t|)$ & \\
\hline (Intercept) & $6.18 \mathrm{E}+01$ & $5.93 \mathrm{E}+00$ & 10.41 & $\begin{array}{l}410< \\
2 \mathrm{e}-16\end{array}$ & $* * *$ & (Intercept) & $1.09 \mathrm{E}+02$ & $1.14 \mathrm{E}+01$ & 9.585 & $<2 \mathrm{e}-16$ & $* * *$ \\
\hline categoryexecutive & $7.92 \mathrm{E}-02$ & $2.83 \mathrm{E}-01$ & 0.28 & 0.78005 & & $\begin{array}{l}\text { categoryGrand } \\
\text { tourer }\end{array}$ & $-6.22 \mathrm{E}-02$ & $2.95 \mathrm{E}-01$ & -0.211 & 0.8331 & \\
\hline categoryfullsize & $2.96 \mathrm{E}-01$ & $2.78 \mathrm{E}-01$ & 1.068 & 0.28659 & & categorysportscar & $-9.46 \mathrm{E}-02$ & $9.18 \mathrm{E}-02$ & -1.03 & 0.3045 & \\
\hline categorymidsize & $-2.09 \mathrm{E}-01$ & $2.82 \mathrm{E}-01$ & -0.74 & 0.45971 & & Year & $-4.96 \mathrm{E}-02$ & 5.79E-03 & -8.571 & $8.02 \mathrm{E}-15$ & $* * *$ \\
\hline categorysportscar & $3.66 \mathrm{E}-01$ & $2.85 \mathrm{E}-01$ & 1.284 & 0.20021 & & $\mathrm{Km}$ & $-9.57 \mathrm{E}-06$ & $1.29 \mathrm{E}-06$ & -7.441 & $5.66 \mathrm{E}-12$ & $* * *$ \\
\hline categorySUV & $2.02 \mathrm{E}-01$ & $2.77 \mathrm{E}-01$ & 0.731 & 0.46567 & & Ps & $4.88 \mathrm{E}-03$ & $4.55 \mathrm{E}-04$ & 10.718 & $<2 \mathrm{e}-16$ & $* * *$ \\
\hline categoryVan & $4.20 \mathrm{E}-01$ & $2.86 \mathrm{E}-01$ & 1.47 & 0.14264 & & Status & $1.06 \mathrm{E}-01$ & $5.85 \mathrm{E}-02$ & 1.812 & 0.0718 & \\
\hline Year & $-2.55 \mathrm{E}-02$ & $2.96 \mathrm{E}-03$ & -8.608 & $7.23 \mathrm{E}-16$ & $* * *$ & Engine & NA & NA & NA & NA & \\
\hline $\mathrm{Km}$ & $-5.53 \mathrm{E}-06$ & $1.24 \mathrm{E}-06$ & -4.459 & $1.23 \mathrm{E}-05$ & $* * *$ & \multirow{4}{*}{\multicolumn{6}{|c|}{ Multiple R-squared: 0.6497 , Adjusted R-squared: 0.6367}} \\
\hline Ps & $3.17 \mathrm{E}-03$ & $2.89 \mathrm{E}-04$ & 10.976 & $<2 \mathrm{e}-16$ & $* * *$ & & & & & & \\
\hline Status & $4.24 \mathrm{E}-02$ & $1.44 \mathrm{E}-02$ & 2.938 & 0.003599 & $* *$ & & & & & & \\
\hline Engine & $-1.36 \mathrm{E}-01$ & $3.50 \mathrm{E}-02$ & -3.892 & 0.000126 & $* * *$ & & & & & & \\
\hline \multicolumn{12}{|c|}{ - --- } \\
\hline \multicolumn{6}{|c|}{ Audi } & \multicolumn{6}{|c|}{ Porsche: } \\
\hline & Estimate & Std. Error & t value & $\operatorname{Pr}(>|t|)$ & & & Estimate & Std. Error & t value & $\operatorname{Pr}(>|t|)$ & \\
\hline (Intercept) & $5.43 \mathrm{E}+01$ & $1.33 \mathrm{E}+01$ & 4.095 & $5.65 \mathrm{E}-05$ & $* * *$ & (Intercept) & $4.53 \mathrm{E}+01$ & $4.66 \mathrm{E}+00$ & 9.723 & $<2 \mathrm{e}-16$ & $* * *$ \\
\hline categoryexecutive & $1.81 \mathrm{E}-01$ & $7.02 \mathrm{E}-02$ & 2.577 & 0.010514 & $*$ & categorysportscar & $1.58 \mathrm{E}-01$ & $4.95 \mathrm{E}-02$ & 3.19 & 0.0016 & $* *$ \\
\hline categoryfullsize & $4.09 \mathrm{E}-01$ & 7.13E-02 & 5.746 & $2.57 \mathrm{E}-08$ & $* * *$ & categorySUV & $-5.16 \mathrm{E}-02$ & $6.57 \mathrm{E}-02$ & -0.785 & 0.4332 & \\
\hline categorymidsize & $2.15 \mathrm{E}-01$ & $6.76 \mathrm{E}-02$ & 3.173 & 0.001694 & $* *$ & Year & $-1.71 \mathrm{E}-02$ & $2.33 \mathrm{E}-03$ & -7.334 & $2.83 \mathrm{E}-12$ & *** \\
\hline categorysportscar & $4.90 \mathrm{E}-01$ & $7.18 \mathrm{E}-02$ & 6.824 & $6.29 \mathrm{E}-11$ & $* * *$ & $\mathrm{Km}$ & $-4.58 \mathrm{E}-06$ & $4.85 \mathrm{E}-07$ & -9.426 & $<2 \mathrm{e}-16$ & *** \\
\hline categorySUV & $3.17 \mathrm{E}-01$ & 7.13E-02 & 4.447 & $1.29 \mathrm{E}-05$ & $* * *$ & Ps & $2.09 \mathrm{E}-03$ & $2.09 \mathrm{E}-04$ & 10.031 & $<2 \mathrm{e}-16$ & *** \\
\hline Year & $-2.17 \mathrm{E}-02$ & $6.57 \mathrm{E}-03$ & -3.3 & 0.001104 & ** & Status & $1.63 \mathrm{E}-01$ & $2.36 \mathrm{E}-02$ & 6.921 & $3.49 \mathrm{E}-11$ & *** \\
\hline $\mathrm{Km}$ & $-6.86 \mathrm{E}-06$ & 7.97E-07 & -8.607 & $7.48 \mathrm{E}-16$ & $* * *$ & Engine & $-4.86 \mathrm{E}-02$ & $6.75 \mathrm{E}-02$ & -0.721 & 0.4716 & \\
\hline Ps & $1.69 \mathrm{E}-03$ & $1.27 \mathrm{E}-04$ & 13.289 & $<2 \mathrm{e}-16$ & $* * *$ & \multirow{2}{*}{\multicolumn{6}{|c|}{ 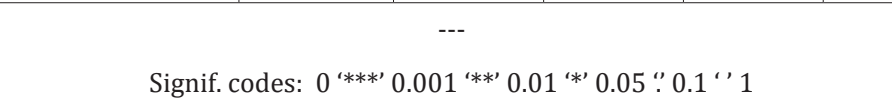 }} \\
\hline Status & $4.24 \mathrm{E}-02$ & $1.44 \mathrm{E}-02$ & 2.938 & 0.003599 & $* *$ & & & & & & \\
\hline Engine & $-1.36 \mathrm{E}-01$ & $3.50 \mathrm{E}-02$ & -3.892 & 0.000126 & $* * *$ & \multirow{3}{*}{\multicolumn{6}{|c|}{ Multiple R-squared: 0.6373 , Adjusted R-squared: 0.6275}} \\
\hline \multicolumn{6}{|c|}{ 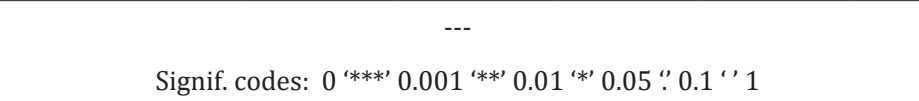 } & & & & & & \\
\hline \multicolumn{6}{|c|}{ Multiple R-squared: 0.6654 , Adjusted R-squared: 0.6524} & & & & & & \\
\hline
\end{tabular}

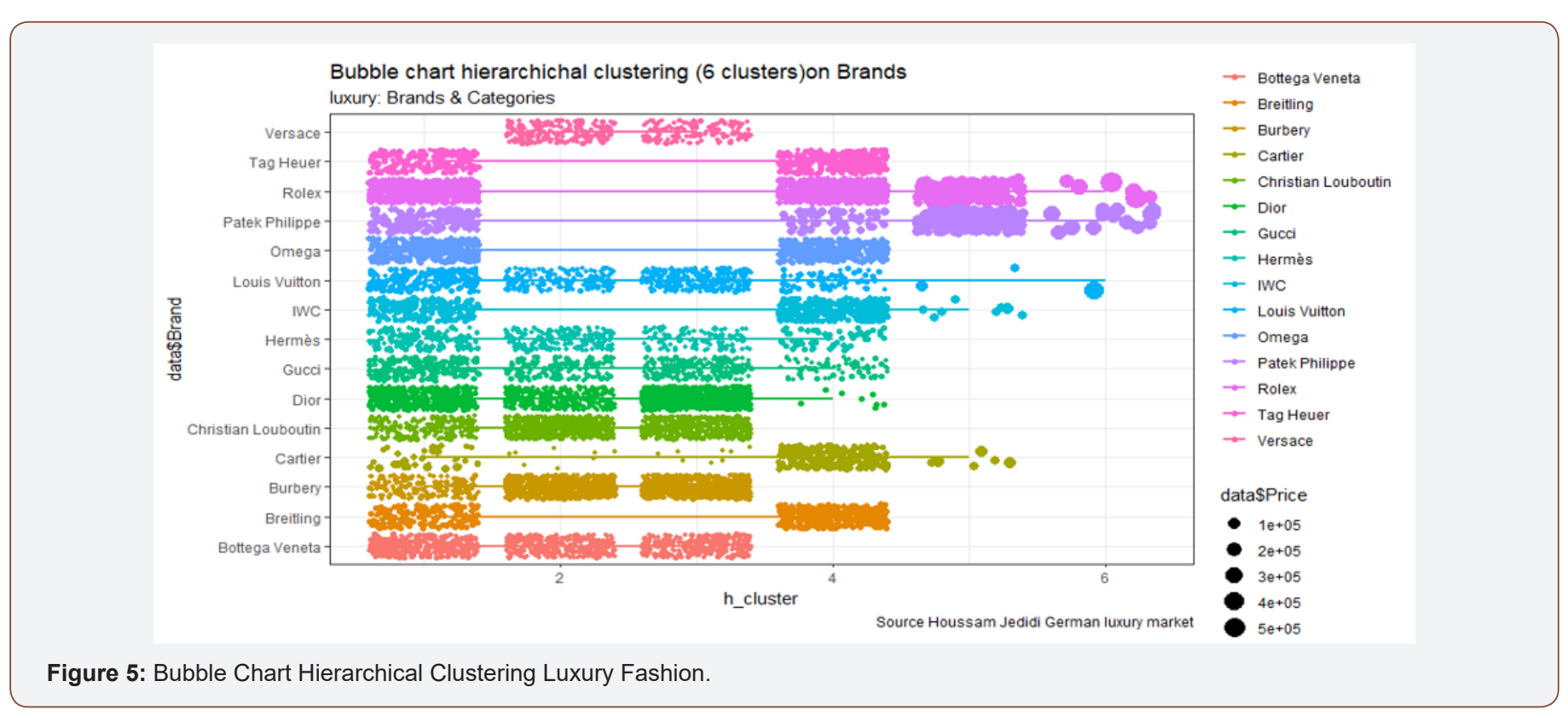


For luxury personal goods, we, likewise, used the available data to better characterize the market for personal luxury goods. The hierarchical clustering method using R suggested the existence of six clusters. The results affirm the role of gender in the market. The output differentiates between entry line and accessible luxuries for men and women. Brands like Bottega Veneta, Gucci, Dior, Hermes and Burberry are covering the left part of the luxury segment with entry, accessible and expensive goods (Figure 5). Other brands such as Breitling, Rolex, Cartier and Tag Heuer are focusing on the upper tier with expensive and ultraluxury products. Exclusivity and expensiveness are major aspects characterizing their philosophy, and therefore their pricing strategies.

Interestingly, and in a sense analogous to the automobile industry, the market for luxury personal goods presents various pricing strategies across all sellers. For example, brands like Dior, Versace, Christian Louboutin are dominating the $2^{\text {nd }}$ and $3^{\text {rd }}$ groups. They are major players in manufacturing bags, shoes, Pret a Porter and Accessories with moderate prices.

Others, like Rolex, Tag Heuer, Hublot, Langer \& Söhne and IWC are dominating the ultra-expensive market. Interestingly, Louis Vuitton is the unique brand which covers all clusters (like MercedesBenz). Besides, the manufacturer has the most expensive product, a "Dentelles de diamond" and a "Dayton" watch for €550.000. Subsequently, from the perspective, we maintain that hypothesis $\mathrm{H} 1 \mathrm{a}, \mathrm{H} 1 \mathrm{~b}$, and $\mathrm{H} 2$ are sustained.

Further, we introduced the source of information to compare the strategies in relationship to exclusivity and rarity and, also, to highlight the effect of the brand's multichannel usage concerning elitism and pricing. The analyses show a major role of choosing either or not to sell production on external platforms. Exclusive brands such as Rolex or Patek Philippe are carefully handling their merchandise and price information as they are typically only available on request for certain clients. Moreover, it has been shown that gender is a significant variable in the segment (Table 1).

More precisely, for both accessories and watches men's articles are significantly more expensive. For bags and jewelry gender has a comparatively slight effect in favor of woman. This amounts to an important finding as it, for example, broadens our knowledge but also contradicts previous insights. That is, the results contradict previous findings like Stockburger-Sauer and Teichmann [26] who affirmed that "the majority of markets and product categories, the price for female luxury brands is significantly higher compared to their compared to their male counterparts".

Without considering the car industry, the luxury market clearly shows higher prices for males in major categories like watches and accessories. Therefore, $\mathrm{H} 4$ is also established. Analogous to the car industry, we selected fashion brands and tried to analyze their pricing strategies according to product characteristics. The result for Louis Vuitton shows a significant difference in pricing luxury categories (Table 3). Accessories build an entry line to the luxury market and are therefore significantly cheaper than other categories. As the pricing model confirms the results of the cluster analysis and empathizes the role of gender in the luxury fashion across various categories and we like to note that convergent validity seems emerging.

Additionally, due to its selected and conservative distribution channels, Louis Vuitton products show a noteworthy difference between selling them on the own web or through foreign platforms. Among other things, this is because the brand doesn't offer any discounts and sells only new products on their website. Nonetheless, other online shops offer a variety of products (new/ used) and have totally different interests than the brand itself (image and exclusivity). For instance, Louis Vuitton carefully handles prestigious and exclusive goods. Price and information of ultra-luxury merchandise are only on request and are individually treated. We also found that, LV accentuated female products which seemingly makes it more of a feminine brand. Without the below mentioned characteristics such gender, category, and source of information $\left(\mathrm{R}^{2} \sim 61 \%\right)$, a Louis Vuitton product has an expected price of around $€ 628$ another intriguing finding.

Interesting results are also shown by the analysis of Hermes and its pricing strategy. Unlike Louis Vuitton, the brand appears to equally serving both genders. Besides, Hermes is prioritizing exclusivity since all the downloaded data comes from the own shop. It was hard to find a foreign shop that is selling new Hermes products among all the selected categories. We found either secondhand-shops or platforms that are occasionally selling some goods such as Perfumes and accessories. Without the selected variables, a Hermes product has an average price of $€ 248\left(\mathrm{R}^{2} \sim 72 \%\right)$, and so succumbs Louis Vuitton.

\section{Conclusions: Insights and Directions for Future Research}

This paper marks a first step to, unlike previous researches that used limited data or data on a very few brands only (e.g. 3-4 brands), exploit online data from numerous manufacturers and across various industries to enhance our understanding about pricing strategies in luxury markets. Our data can be viewed to provide a rather complete image of a variety of luxury markets and even industries. As a result, much external validity can be expected from our insights.

Also, the outcomes reiterate the existence of categoryspecialized companies such as Hublot, IWC in ultraluxury; Dior, Hermes, Burberry, Cartier, Gucci and Bottega Veneta in female/ male entry line, affordable and expensive luxury. Of particular interest seems our findings related to Louis Vuitton. The brand appears to be rather feminine and, thus, appears to have a unique differentiation relative to Hermes. In addition, it is interesting to note that both brands serve both genders equally.

Another interesting insight entails that Louis Vuitton succeeds in simultaneously covering practically all categories employing 
true luxury-level pricing. Next, we find that extra features and high differentiation degree are major factors to compete in the luxury sector. To illustrate, Mercedes-Benz, as a premium manufacturer, succeeded to cover the entire luxury car market but, on top of that, through exclusive and limited offerings such as stretched and armored G-class or a limited SLR tapped into the luxury market or even the ultrahigh luxury market.

We also find that traditional, renowned and successful premium ones have the potential to successfully compete in the market for high-end goods. Sometimes, they manage to charge even higher prices than luxury dynasties. This relates to the concept of a vertical extension strategy. Premium brands like BMW, Audi and Mercedes offer luxury lines for their loyal clients as they seek to broaden the portfolio of cars, preferably within the brand, e.g. an owner of Porsche 911 sportscar would like to also have a Porsche SUV, etc.

Our analyses reveal rather interesting pricing philosophies . To illustrate, Mercedes is minimally differentiating its pricing approach according to categories (SUV, full-size sedans, etc.). Therefore, the brand suits customers who, primarily, seek identification and reference ("I drive a Benz"). However, BMW and Audi are more activive in drawing boundaries between their own categories in an effort to become more attractive for clients who look for differentiation. Subsequently, someone who owns an Audi RS6 is willing to reflect higher social values in relation to an S4 driver.

The analyses highlighted the role of brand value in choosing a suitable pricing strategy. Consequently, traditional, well-known and renowned brands are authentic and legitimate to charge premium prices for their merchandise across all categories compared to their counterparts. Overall, we maintain that our findings, while building on previous research, question the extend knowledge along the lines of which brands-premium or luxury--do indeed charge the highest prices. Also, we shed light into the question if it is helpful to offer many or all products within a category. Importantly, we also offer new insights as to type of gender-specific pricing strategies are executed.

As stated, this research marks a first step toward a better understanding of prestige pricing. Thus, depicting a few fundamental directions for future research on prestige pricing seem to be in order. First, future investigations on prestige pricing should focus on the evolution of prestige pricing strategies over time. Especially interesting-and methodologically challenging appear projects that try to assess and model competitive interplay between or even among luxury producers. Importantly, it should be noted that the pricing variable is of special, sometimes seemingly limited interest to luxury managers. This seems to hold true since pricing should be high to maintain a luxurious cache as well as luxurious margins. However, consistent with economics-based cartel theory, such pricing should attract entry and, especially, entrants who may wish to violate the possibly tacitly agreed luxuriously high prestige pricing. Along these lines, it might be of interest to conduct market overviews and investigate companies' conduct in situations such as the aforementioned.

Next, it would be interesting, important and doable to investigate which product-market combinations would lend themselves "best" to prestige pricing. In this context, it might very well be that distinct consumer preferences may play a role, e.g. the existence of a sizeable segment of snobs in a given product-market combination. This may very well be as snobs exhibit most unique preferences structures facilitating prestige pricing. That way, product-market combinations could be linked to prestige pricing as well as to certain consumer preferences and types.

\section{References}

1. Pohland L, Kesgin M (2018) Pricing determinants in hotels: The case of luxury, upscale, and mid-scale price segments. Journal of Revenue Pricing Management 17: 218-230.

2. Hinterhuber A, Liozu S M (2018) Thoughts: premium pricing in B2C and B2B. Journal of Revenue Pricing Management 17: 301-305.

3. Kumku E, McClure J E (2003) Explaining Prestige Pricing: An Alternative to Back-Bending. Marketing Education Review 13(1): 49-57.

4. Hawkins E D (1954) Price Policies and Theory. Journal of Marketing 18(3): 219-232.

5. Vigneron E, Johnson L W (1999) A Review and a Conceptual Framework of Prestige-Seeking Consumer Behavior. Academy of Marketing Science Review 1: 1-17.

6. Perrault W D, McCarthy E J (1999) Basic Marketing: A Global-Managerial Approach. (13 ${ }^{\text {th }}$ edn), Irwin McGraw-Hill, Boston, USA.

7. Kapferer, J N, Klippert C, Leproux C (2014) The minimum price of luxury: an explanatory study. Journal of Revenue and Pricing Management 13: 2-11.

8. Bain and Company (2017) Luxury Goods Worldwide Market Study, FallWinter.

9. Oancea $O$ (2016). Challenging of pricing luxury in commercial aviation - will first class disappear? Journal of Revenue and Pricing Management 17(4): 296-300.

10. Yeoman I, McMahon Beattie U (2005) Luxury markets and premium pricing. Journal of Revenue and Pricing Management 4(4): 319-328.

11. Mercedes Benz (2006) Preise für die C-Klasse Limousinen. Daimler Chrysler AG Stuttgart, VP/VP 0260. 0406/33, Federal Republic of Germany.

12. Mercedes Benz (2008) Preise für die C-Klasse Limousinen. DaimlerChrysler AG Stuttgart, VP/VC 0260. 0408/32, Federal Republic of Germany.

13. Mercedes-Benz (2017). C-Klasse Limousine. Daimler AG, MBD/VPP 0101. 0317/73, Ausgabe 1. Gedruckt in der Bundesrepublik Deutschland. Found under: www.Mercedes-benz.de

14. Harkison T, Hemmington N, Hyde K F (2017) Luxury accommodation significantly different or just more expensive. Journal of Revenue and Pricing Management 17(4): 231-243.

15. Milburn R, Hill L (2007) Hospitality Directions European Edition. Pricewaterhouse Coopers, London.

16. Johnoson MD, Olsen L L, Andreassen TW (2009) Joy and disappointment in the hotel experience: Managing relationship segments. Managing Service Quality 19(1): 4-30.

17. Harkison T (2018) The meaning of luxury in the tourism, hospitality and events. Journal of Revenue Pricing Management 17: 306-307. 
18. Kapferer J N, Tabatoni 0 (2011) Is luxury really a financial dream? Journal of Strategic Management Education 7(14): 1-16.

19. Fassnacht M, Kluge PN, Mohr H (2013) Pricing Luxury Brands: Specificities, Conceptualization and Performance Impact. Marketing 2(2): 104-117.

20. Kapferer, J N (2012) Abundant rarity: The key to luxury growth. Business Horizons 55: 453-462.

21. Kapferer J N (2010) Luxury after the crisis: Pro logo or no logo? European Business Review.

22. De Block A, Dewitte S. (2007) Mating games: cultural evolution and sexual selection. Biology and Philosophy 22: 475-91.
23. Griskevicius V, Tybur J M, Sundie J M, Cialdini RB, Miller G F, Kenrick D T (2007) Blatant benevolence and conspicuous consumption: when romantic motives elicit strategic costly signals. Journal of Personality and Social Psychology 93(1): 85-102.

24. Buss D M (1989) Sex differences in human mate preferences: evolutionary hypotheses tested in 37 cultures. The Behavioral and Brain Sciences 12: 1-49.

25. Kapferer J N (2014) The future of luxury: Challenges and Opportunities. Journal of Brand Management, 21(9): 716-726.

26. Stockburger Sauer N E, Teichmann K (2013) Is luxury just a female thing? The role of gender in luxury brand consumption. Journal of Business Research 66(7): 889-896. 